\title{
Effect of Nursing Interventions on the Severity of Orthostatic Hypotension among Older Adults Residing in Assisted Living Facilities
}

\author{
Abeer Ramadan Awade Gamaa, Assistant Lecturer \\ Gerontological Nursing, Faculty of Nursing, Damanhour University
}

Nagwa Abd El Fattah Ibrahim, Professor

Gerontological Nursing, Faculty of Nursing, Alexandria University

Thoraya Mohamed Abdelaziz, Assistant Professor

Medical Surgical Nursing, Faculty of Nursing, Alexandria University

\begin{abstract}
Orthostatic hypotension $(\mathrm{OH})$ is a predominant insufficiently evaluated and treated problem among older people. In this context, it is important for the gerontological nurses to assess and manage $\mathrm{OH}$ to avoid its serious consequences. Objective: Determine the effect of nursing interventions on the severity of orthostatic hypotension among older adults. Settings: Two assisted living facilities affiliated to the Ministry of Social Solidarity, Egypt were selected. Subjects: Forty older adults who were eligible for the study. Tools: Five tools were used: Saint Louis University Mental Status (SLUMS) Examination, Geriatric Depression Scale Short-Form (GDS-SF), Orthostatic Vital Signs Measurement Scale, Older Adults Socio-Demographic and Clinical Data Structured Interview Schedule, and Orthostatic Hypotension Grading Scale. Results: A statistical significant increase in standing blood pressure was found post interventions compared to pre interventions. As well as, a highly significant improvement of $\mathrm{OH}$ symptoms among older adults was declared. Conclusion: Nursing interventions resulted in a statistically significant increase in standing blood pressure and improved the $\mathrm{OH}$ symptoms among older adults. Recommendations: In-service health education program about $\mathrm{OH}$ has to be offered on regular basis to the nurses at the different assisted living facilities.
\end{abstract}

Keywords: Nursing Interventions; Orthostatic Hypotension; Older Adults; Assisted Living Facilities.

\section{Introduction}

Orthostatic hypotension $(\mathrm{OH})$ is a common syndrome among older adults; that is defined a reduction in systolic blood pressure (SBP) of $20 \mathrm{mmHg}$ or diastolic blood pressure (DBP) of $10 \mathrm{mmHg}$ within 3 minutes of standing. $\mathrm{OH}$ increases with age, due to a decrease in autonomic nervous system function. Treatment of $\mathrm{OH}$ is often challenging divided into non pharmacological and pharmacological approaches. The gerontological nurses play a key role assessing $\mathrm{OH}$ symptoms (syncope, dizziness, vision changes, and cognitive impairment), which may contribute to serious complications, maximizing safety; and providing conservative treatment as: adequate hydration, elevating the bed's head and educating about ways to avoid occurrence

(Nahyun, Jooyeon; Hyunjung; Deok\& Hyunwook, 2020).

\section{Operational definitions:}

Assisted living facilities (AlFs): In this study, refer to a type of housing designed for people who need various levels of medical and personal care namely "elderly homes".

Nursing Interventions: It refers to three different procedures to reduce severity of $\mathrm{OH}$ and associated symptoms namely "Bolus of water, Physical counter maneuvers, and Supine leg exercise". 


\section{Aim of the Study}

This study aims to determine the effect of nursing interventions on the severity of $\mathrm{OH}$ among older adults residing ALFs.

\section{Research Hypothesis}

Older adults residing in ALFs who receive the three proposed nursing interventions will represent lower score on the orthostatic hypotension grading scale than before.

\section{Materials and Method}

\section{Materials}

Design: A quasi-experimental research design was used.

Settings: The study was carried out in two ALFs namely Dar-El Hedaya and Dar-EL Mouwasah.

Subjects: A convenient sample of all older adults residing in the above mentioned settings at the time of the study, and fulfilling the researcher's inclusion criteria. Based on inclusion criteria, the eligible number of older adults for the study was forty.

Tools: In order to collect the necessary data, five tools were used:

\section{Tool I: Saint Louis University Mental} Status (SLUMS) Examination

This tool was developed by Tariq et al., in 2006 and used to identify older adults with cognitive impairment. Its score is 30point assessing eleven cognitive domains. Scoring depended on the respondent's level of education; in case of "High school education", scores ranged from 1 to 30 and classified as follows; older adults scoring from1-20 were considered dementia, 21-26 mild neurocognitive disorder, and from 27 30 have normal response. While, if "less than high school education", scores ranged from 1-30 and classified as; older adults scoring 1-19 were considered dementia, from 20-24 mild neurocognitive disorder, and 25 - 30 normal response.
Moreover, the researcher added "illiterate respondents score" in which; older adults scoring from 1-18 have dementia, 1923 mild neurocognitive disorder, and from 24-30 have normal response.

Tool II: Geriatric Depression Scale ShortForm (GDS-SF)

The GDS-SF was developed by Yesavage et al., in 1983 to assess depression and general well-being in the older adults. The respondent chose the best answer for each statement; either "Yes" and took score one (1) or "No" with a score zero (0) for how he/she has felt over the past week.

\section{Tool III: Orthostatic Vital Signs Measurement Scale}

It was developed by The Agency for Healthcare Research and Quality in 2013 to measure blood pressure, pulse rate and include questions related to symptoms for patients who were at risk for hypovolemia, or had or near syncope symptoms, or at risk for falls.

The older adults was considered having $\mathrm{OH}$ when there was a drop of $\geq 20 \mathrm{~mm} \mathrm{Hg}$ in systolic or $\geq 10 \mathrm{~mm} \mathrm{Hg}$ in diastolic blood pressure, or the pulse is increased of at least 30 beats/minute; after 3 minutes of standing.

\section{Tool IV: Older Adults Socio- Demographic and Clinical Data Structured Interview Schedule}

This tool was developed by the researcher based on in-depth review of recent relevant literatures to collect the socio-demographic and clinical data from the residence medical record.

\section{Tool V: Orthostatic Hypotension Grading Scale}

It was developed by Schrezenmaier et al., in 2005 to assess the frequency and severity of orthostatic symptoms, relationship of symptoms to orthostatic stressors, and impact of symptoms on activities of daily living and standing time. The items were scored on a 5 points Likert scale from (0) to (4). Scores for each item 
were summed to provide a total score which classified as; older adults scoring 0 were considered to have no symptoms, those from 1 to 7 have mild symptoms, those from 8 to 14 have moderate symptoms, and those from 15 to 20 have severe symptoms.

\section{Method}

- The study was carried out in three phases:

\section{Preparation phase:}

- Where the researcher obtained the study approval from the responsible authorities, preparing the study tools to collect the necessary data, performing pilot study, and prepared the program education materials.

\section{Implementation phase:}

- The study subjects were interviewed individually by the researcher in the ALFs after explaining the study aim.

- The researcher implemented the proposed nursing interventions in 5 sessions. The first session the researcher screened all older adults to determine their eligibility for the study; in the second one the researcher gave the older adults simple information about $\mathrm{OH}$.

- In the third, fourth and fifth sessions, the researcher implemented bolus of water drinking, standing cross legged and supine leg exercise interventions.

- Prior to the implementation of the interventions; the researcher asked the study older adults to refine from caffeine, nicotine and encouraged them to eat a light breakfast.

- Data collection started from the beginning of February to the end of April 2021.

\section{Evaluation phase:}

- The researcher evaluated the effect of the program nursing interventions two times as follow: The first evaluation was done immediately after implementing the proposed nursing interventions, and the second one was done after two weeks of implementing the last nursing intervention session by measuring the $\mathrm{OH}$, the frequency and severity of orthostatic symptoms. Using tool III, and V.

\section{Ethical considerations:}

An informed written consent was obtained from each study subject after explanation of the study purpose. Study subject's privacy and confidentiality of the collected data was maintained.

\section{Statistical Analysis}

Data were analyzed using the statistical package for social science SPSS (version 20 ). The level of significance was $\leq 0.05$ level.

\section{Results}

Table (1): regarding the age of the studied older adults, $(80 \%)$ of the elders was sixty to less than seventy five years, and (20\%) were seventy five to less than eighty five years. Regarding the older adults gender, the result revealed that; $(52.5 \%)$ were males. Concerning the educational level, $(25 \%)$ had basic education, $(22.5 \%)$ were able to read and write, $(20 \%)$ completed secondary education, (17.5\%) had university education and above, while $(15 \%)$ were illiterate.

Table (2) shows that the mean standing systolic blood pressure before the implementation of the three interventions were $(104.00 \pm 17.36,108.75 \pm 15.22,107.75 \pm 18.19)$ respectively. While, improved immediately after $\quad(132.50 \pm 14.63, \quad 123.00 \pm 15.72$, $125.88 \pm 17.93$,) respectively. There was a highly statistically significant difference between the standing SBP before and immediately after the implementation of the three intervention $(\mathrm{P}=0.000)$, and a statistically significant difference between the standing DBP before and immediately after the bolus of water drinking and supine leg exercise interventions ( $\mathrm{P}=0.001,0.023)$ respectively. Regarding the severity of $\mathrm{OH}$ associated symptoms before drinking bolus of water, the 
table shows a highly statistically significant difference between the $\mathrm{OH}$ symptoms before and immediately after the implementation of the three interventions $(\mathrm{P}=0.000)$.

Table (3) shows that; the mean scores of the standing systolic and diastolic BP before and after two weeks of nursing interventions were $(110.50 \pm 24.59,69.75 \pm 14.05)$ and (119.25 $\pm 11.63,77.25 \pm 7.506)$ respectively. A statistically significant difference was noted between the standing SBP and DBP before and after two weeks of implementing nursing interventions $(\mathrm{P}=0.045, \mathrm{P}=0.004)$ respectively. As for the laying blood pressure, no statistically significant difference between the laying SBP and DBP $(\mathrm{P}=0.949, \quad 0.645)$ respectively before and after two weeks implementing the nursing interventions. A highly statistically significant difference was declared between $\mathrm{OH}$ symptoms before and after two weeks of nursing interventions $(\mathrm{P}=0.000)$.

\section{Discussion}

Orthostatic hypotension $(\mathrm{OH})$ is associated with an increased risk of negative health consequences including cardiovascular diseases, falls, mortality, and cognitive impairment (Kim et al., 2020). However, the present study results revealed that; bolus of water intervention was effective in reducing $\mathrm{OH}$ and related symptoms (Table 2). This finding may be related to the fact that; drinking bolus of water expands plasma volume and elicits a significant pressor effect that increases the standing SBP. This is in line with other studies finding which reported that; drinking bolus of water increases standing BP which reduces the $\mathrm{OH}$ and its symptoms. (Newton\& Frith., 2018; Frith, 2017). In contrast Senard et al, (1999) reported that; ingestion of $500 \mathrm{ml}$ water did not change orthostatic BP when measured $60 \mathrm{~min}$ after fluid intake in patients with Parkinson's disease (PD) and neurogenic orthostatic hypotension.

In relation to the effect of standing cross legged intervention on $\mathrm{OH}$ and associated symptoms, the current study results showed; standing cross legged improved standing BP and associated $\mathrm{OH}$ symptoms (Table 2).This finding may be explained by the fact that crossing one's legs while standing improves systemic venous return, resulting in increased heart rate and BP. This finding is supported by Kim, Choi, Won, \& Kim, (2015) who revealed that; leg crossing effectively reduces $\mathrm{OH}$ without additional cost. Conversely, Newton \& Frith, (2018) reported standing cross legged doesn't affect SBP drop neither $\mathrm{OH}$ symptoms.

Regarding the effect of supine leg exercise on $\mathrm{OH}$ and associated symptoms (Table 2), the present study finding revealed a highly statistically significant difference between the standing SBP before and immediately after the implementation of supine leg exercise intervention. This interpreted as; performing exercise minimizes venous pooling and expands plasma volume, thus exercise training may be beneficial to improve orthostatic symptoms. The findings are supported by Kanegusuku, et al., (2017). On the other hand; Zion, et al., (2004) reported that; a home based resistance training program using elastic bands effectively increases dynamic muscle strength in elderly with $\mathrm{OH}$. With no changes in orthostatic BP, this could be attributed to the limited length of the program. In addition to the three interventions, there were some instructions included in the educational session and help in achieving the aim of the study (Table 3). These instructions included sleeping with the head up, decreasing the size of the meals and decreasing the amount of carbohydrates in meals, avoiding hot weather This result is in line with the findings of other studies done by (Cooper, \&Hainsworth,2008; Son,\& Lee ,2015; Stotz, et al ,2014).

\section{Conclusion}

The study hypothesis is supported by the findings of the present study, thus it can be concluded that; implementing the studied nursing interventions resulted in a statistically significant increase in standing BP and improved the $\mathrm{OH}$ symptoms among older adults.

\section{Recommendations}

- In-service health education programs about $\mathrm{OH}$ to be planned and offered on regular basis to the nurses at the different ALFS. 
Table (1): Frequency distribution of the studied older adults according to their sociodemographic characteristics

\begin{tabular}{||l|l|c|c||}
\hline \multirow{2}{*}{ Socio-demographic characteristics } & \multicolumn{2}{c|}{ Total (N=40) } \\
\cline { 2 - 4 } & Age (years) & Frequency & Percent (\%) \\
& $\geq 75$ & 32 & 80.0 \\
Gender & Male & 8 & 20.0 \\
\hline Marital status & Female & 21 & 52.5 \\
& Married & 19 & 47.5 \\
\hline Level of education & Widowed & 1 & 2.5 \\
& Divorced & 26 & 65.0 \\
& Single & 8 & 20.0 \\
& Basic education & 5 & 12.5 \\
\hline Work status & Read \& write & 10 & 25.0 \\
& Secondary education & 9 & 22.5 \\
& University education & 8 & 20.0 \\
& Illiterate & 7 & 17.5 \\
\hline Length of stay at elderly home & Skilled work & 18 & 15.0 \\
(years) & Employee & 12 & 45.0 \\
& No work / house wife & 10 & 30.0 \\
\hline With whom live at elderly & 5<10 & 26 & 25.0 \\
\hline home & $\geq 10$ & 10 & 65.0 \\
& Alone & 4 & 25.0 \\
\hline \hline
\end{tabular}


Table (2): Comparison of the mean orthostatic hypotention score and the severity of associated symptoms among the studied older adults before and immediately after drinking bolus of water

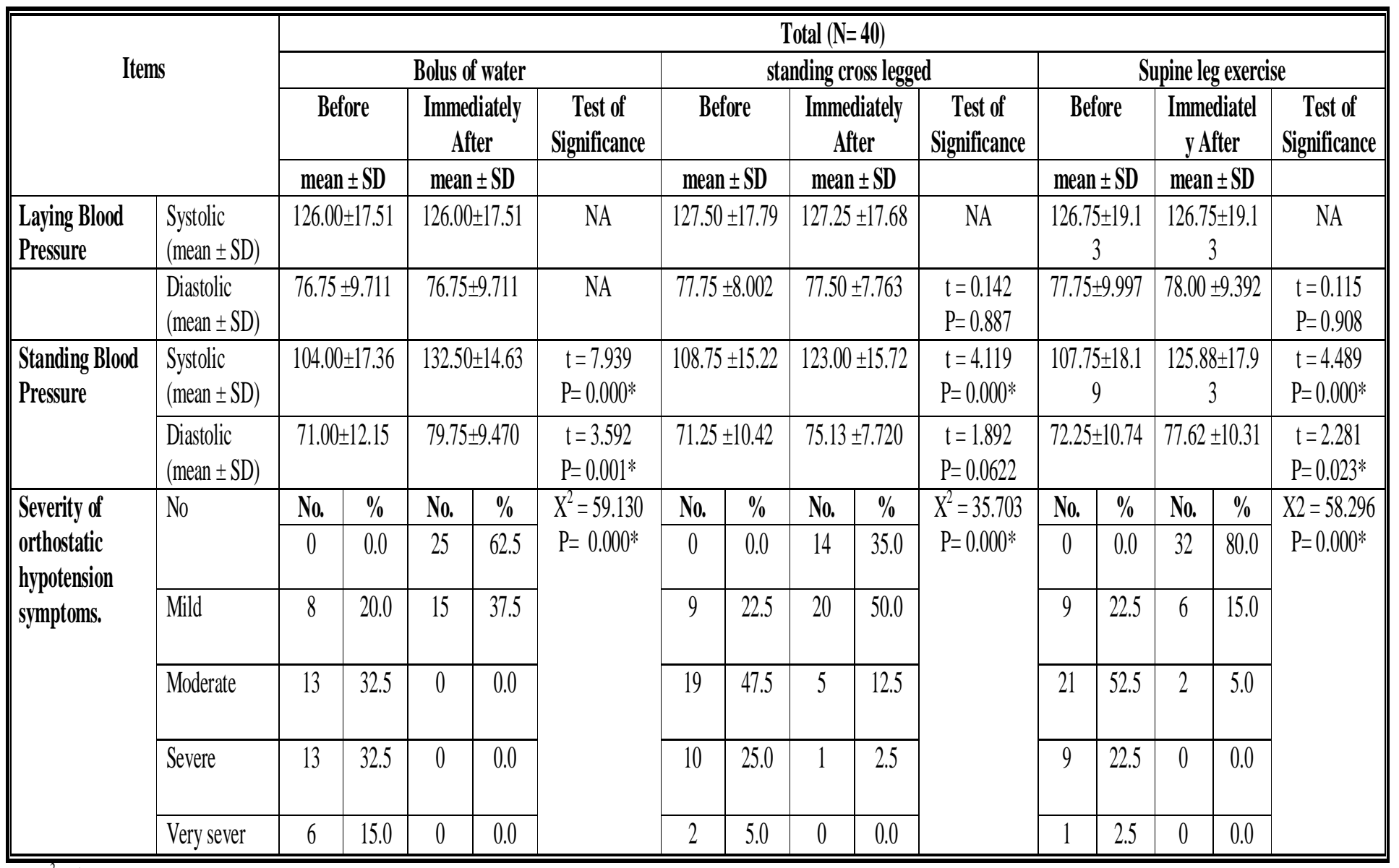

$X^{2}:$ Chi Square Test

T: Paired TTest

* Statistically significant at $p \leq 0.05$

\# Multiple responses were allowed

NA: test of significance is not applicable 
Table (3): Comparison of the mean orthostatic hypotention score and the severity of associated symptoms among the studied older adults before and after two weeks of nursing interventions implementation

\begin{tabular}{|l|l|c|c|c|c||}
\hline Items & \multicolumn{1}{|c|}{ Before } & After 2 weeks & $\begin{array}{c}\text { Test of } \\
\text { significance }\end{array}$ & $\begin{array}{c}\text { Effect size } \\
\text { Cohen's D }\end{array}$ \\
\cline { 3 - 6 } & Mean \pm SD & Mean \pm SD \\
\multirow{2}{*}{$\begin{array}{l}\text { Laying } \\
\text { Plood }\end{array}$} & SBPsure & $127.75 \pm 21.78$ & $127.50 \pm 11.49$ & $\begin{array}{c}\mathrm{t}=0.064 \\
\mathrm{P}=0.949\end{array}$ & 0.014 \\
\cline { 2 - 6 } & DBP & $77.75 \pm 11.65$ & $78.75 \pm 7.228$ & $\begin{array}{c}\mathrm{t}=0.461 \\
\mathrm{P}=0.645\end{array}$ & 0.103 \\
\cline { 2 - 6 } & HR & $69.73 \pm 5.607$ & $74.63 \pm 6.975$ & $\begin{array}{c}\mathrm{t}=3.463 \\
\mathrm{P}=0.001^{*}\end{array}$ & 0.774 \\
\hline $\begin{array}{l}\text { Standing } \\
\text { Blood } \\
\text { Pressure }\end{array}$ & SBP & $110.50 \pm 24.59$ & $119.25 \pm 11.63$ & $\begin{array}{c}\mathrm{t}=2.034 \\
\mathrm{P}=0.045^{*}\end{array}$ & 0.455 \\
\cline { 2 - 6 } & DBP & $69.75 \pm 14.05$ & $77.25 \pm 7.506$ & $\begin{array}{c}\mathrm{t}=2.978 \\
\mathrm{P}=0.004^{*}\end{array}$ & 0.666 \\
\cline { 2 - 6 } & HR & $75.70 \pm 6.136$ & $80.40 \pm 6.071$ & $\begin{array}{c}\mathrm{t}=3.407 \\
\mathrm{P}=0.001^{*}\end{array}$ & 0.770 \\
\hline $\begin{array}{l}\text { Systolic } \\
\text { OH }\end{array}$ & $\begin{array}{l}\text { Mean Difference } \\
\text { between SBP } \\
\text { lying and } \\
\text { standing position }\end{array}$ & $17.25 \pm 11.31$ & $8.250 \pm 4.465$ & $\begin{array}{c}\mathrm{t}=4.681 \\
\mathrm{P}=0.000^{*}\end{array}$ & 1.046 \\
\hline $\begin{array}{l}\text { Diastolic } \\
\text { OH }\end{array}$ & $\begin{array}{l}\text { Mean Difference } \\
\text { between SBP } \\
\text { lying and } \\
\text { standing position }\end{array}$ & $8.000 \pm 6.485$ & $1.500 \pm 3.616$ & $\begin{array}{c}\mathrm{t}=5.537 \\
\mathrm{P}=0.000^{*}\end{array}$ & 1.238 \\
\hline $\begin{array}{l}\text { Total severity of OH mean } \\
\text { score }\end{array}$ & $10.97 \pm 5.299$ & $2.670 \pm 2.556$ & $\begin{array}{l}\mathrm{t}=8.923 \\
\mathrm{P}=0.000^{*}\end{array}$ & 1.995 \\
\hline
\end{tabular}

SBP: systolic blood pressure

DBP: diastolic blood pressure

HR: heart rate

$\mathrm{OH}$ : orthostatic hypotention 


\section{References}

- Agency for Healthcare Research and Quality. (2013). Preventing Falls in Hospitals (Tool 3F: Orthostatic Vital Sign Measurement). Available at: https://www.ahrq.gov/professionals/systems/ hospital/fallpxtoolkit/fallpxtk-tool3f. $\quad \mathrm{html}$. Retrieved on: 10 May 2020.

- Cooper, V. L, \& Hainsworth, R.(2008). Head-up sleeping improves orthostatic tolerance in patients with syncope. Clinical Autonmic Research Journal; 18(6):318-324. doi: 10.1007/s10286-008-0494-8. Epub 2008 Oct 15. PMID: 19015909.

- Elhusseini, S. (2013). Effect of self-care intervention on quality of life of older adults with heart failure. Unpublished doctoral thesis. Alexandria University, Faculty of Nursing.

- Frith, J. (2017) Bolus water drinking for orthostatic hypotention in older people: a phase 2 study. Age and Ageing Journal, 46(2), Page ii9. doi.org/10.1093/ageing/afx107.30.

- Kim, N., Park, J., Hong, H., Kong, I. D., \& Kang, H. (2020). Orthostatic hypotension and health related quality of life among community living older people in Korea. Quality of Life Research Journal; 29(1):303312. . doi: 10.1007/s11136-019-02295- 6.

- $\quad$ Kim, S. S., Choi, K. S., Won, S.S., Kim, I. Y. (2015). The Effect of Leg Crossing on Reducing Orthostatic Hypotension in Hemodialysis Patients. Journal of Muscle and Joint Health; 22(3):160-166. doi:10.5953/JMJH.2015.22.3.160.

- Kanegusuku, H., Silva-Batista, C., Peçanha, T., Nieuwboer, A., Silva, N. D Jr, et al., (2017).Effects of Progressive Resistance Training on Cardiovascular Autonomic Regulation in Patients with Parkinson Disease: A Randomized Controlled Trial. Archives of Physical Medicine and Rehabilitation; 98(11):2134-2141. doi: 10.1016/j.apmr.2017.06.009.

- Newton,J. L., \& Frith, J.(2018). The efficacy of nonpharmacologic intervention for orthostatic hypotension associated with aging. Journal of Neurology; 91(7): e652-e656.doi: 10.1212/WNL.0000000000005994.

- Nahyun, K; Jooyeon, P; Hyunjung H; Deok, K. I; Hyunwook, K. (2020).Orthostatic hypotension and health-related quality of life among community-living older people in
Korea. Quality of Life Research; 29 (1): 303312. doi:10.1007/s11136-019-02295-6

- Stone L.E., Granier K.L., Segal D.L. (2019) Geriatric Depression Scale. In: Gu D., Dupre M. (eds) Encyclopedia of Gerontology and Population Aging. Springer, Cham. Available at: https://doi.org/10.1007/978-3-319-698922_736-1. Retrieved on: 6/2020.

- Schrezenmaier, C., Gehrking, J. A., Hines, S. M., Low, P. A., Benrud-Larson L. M., etal. (2005).Evaluation of orthostatic hypotension: relationship of a new self-report instrument to laboratory-based measures. Mayo Clinic Proceeding Journal; 80(3): 330-4.

- Senard, J., Brefel, C., Carel, C., Tran, M., Montastruc, J. (1999). Water drinking and the heart. Lancet Journal; 353(9168):1971-1972. doi: 10.1016/S0140-6736(05)77182-8.

- Son, J. T, RN, Lee RNE.(2015). Effects of the amount of rice in meals on postprandial blood pressure in older people with postprandial hypotension: a within-subjects design. Journal of Clinical Nursing; 24 (1516):2277-2285.doi.org/10.1111/jocn. 12864 .

- Stotz, A., Rapp, K., Oksa, J., Skelton, D. A., Beyer, N., et al. (2014). Effect of a brief heat exposure on blood pressure and physical performance of older women living in the community-a pilot-study. International Journal of Environmental Research and Public Health; 11(12):12623-12631. doi: 10.3390/ijerph111212623.

- Tariq, S. H., Tumosa, N., Chibnall, J. T., Perry, M. H., \& Morley, J. E. (2006). The Saint Louis University Mental Status (SLUMS) examination for detecting mild cognitive impairment and dementia is more sensitive than the mini mental state exam (MMSE) a pilot study. American Journal Geriatrician Psychiatry; 14:900-10.

- Yesavage, J. A., Brink, T. L., Rose, T. L., Lum, O., Huang, V., et al. (1983). Development and validation of a geriatric depression screening scale: a preliminary report. Journal of Psychiatric Research; 17(1):37-49.

- Zion, A. S., De Meersman, R., Diamond, B. E., \& Bloomfield, D. M. (2003). A homebased resistance-training program using elastic bands for elderly patients with orthostatic hypotension. Clinical Autonomic Research; 13(4):286-292. doi: 10.1007/s10286-003-0117-3. 